\title{
Zinc-Nickel Alloy Electrodeposition - Influence of Triethanolamine
}

\author{
V. Ravindran * and V.S. Muralidharan \\ Central Electrochemical Research Institute, Karaikudi 630 006, Tamil Nadu, India \\ Received 16 January 2006; accepted 19 November 2006
}

\begin{abstract}
Compared to pure zinc plating, zinc alloys provide several advantages. A zinc alloy generally offers superior sacrificial protection to steel since it corrodes more slowly than pure zinc. A search for a non-cyanide zinc plating bath resulted on the development of a zinc nickel sulphamate bath. To obtain better quality zinc-nickel deposits, triethanolamine was added to the bath. In this paper the influence of triethanolamine in zinc-nickel plating from sulphamate bath has been investigated through current efficiency measurements, cyclic voltammetry, scanning electron microscope, and X-ray diffraction techniques. In the presence of triethanolamine in the zinc-nickel sulphamate bath the current efficiency of alloy deposition increased to a maximum of $99 \%$ at the current density of $1.5 \mathrm{Adm}^{-2}$ and thereafter decreased. TEA adsorbed on the electrode surface obeying Henry's isotherm. On mild steel surfaces, uniform smooth slate gray deposit with smaller crystallites was produced, in presence of TEA in solution, and the electrodeposits exhibited additional $\mathrm{Zn}(\mathrm{OH})_{2}$ and $\gamma-\mathrm{Ni}_{3} \mathrm{Zn}_{22}$ phases. Hydrogen evolution was suppressed by TEA and thereby current efficiency is increased for alloy deposition.
\end{abstract}

Keywords: cyclic voltammetry, electrodeposition, triethanolamine, XRD, Zn-Ni.

\section{Introduction}

Precoated electrogalvanised $\mathrm{Zn}-\mathrm{Ni}$ sheet has offered the automotive and computer industries a superior prefabricated stock resulting in much-improved corrosion resistance. The zinc-nickel alloy deposit has $90-95 \%$ zinc [1] and the deposition is anomalous, i.e., the less noble metal, zinc, deposits preferentially. There are broadly two types of plating baths for $\mathrm{Zn}-\mathrm{Ni}$ alloy, namely the acid type and the alkaline type [2,3]. The acid bath consists of a mixture of zinc and nickel salts, electrolytes, buffers and optional brighteners. In the alkaline type,

\footnotetext{
* Corresponding author. E-mail address: visalakshi47@yahoo.com
} 
the electrolyte consists of $\mathrm{NaOH}$ and additives to maintain the metal species in solution.

The present communication deals with the influence of triethanolamine on the physicochemical characteristics of $\mathrm{Zn}-\mathrm{Ni}$ alloy deposits obtained from sulphamate baths.

\section{Experimental}

Cold rolled steel plates were degreased with trichloroethylene and alkaline electrocleaned cathodically for 2 minutes and anodically for $30 \mathrm{~s}$ in a solution of $35 \mathrm{~g} / \mathrm{L} \mathrm{NaOH}+25 \mathrm{~g} / \mathrm{L} \mathrm{Na}_{2} \mathrm{CO}_{3}$ at $30{ }^{\circ} \mathrm{C}$. They were washed in running water and given a dip for $10 \mathrm{~s}$ in $5 \% \mathrm{H}_{2} \mathrm{SO}_{4}$ solutions. Finally they were thoroughly washed in deionized water and drying was resorted too.

\section{Electrodeposition}

Electrodeposition was carried out using a regulated power supply as a direct current source, a calibrated ammeter along with a cell. Prepared mild steel panels $(10 \times 7.4 \times 0.05 \mathrm{~cm})$ were used as cathodes. Electrolytic zinc was used as anode material. The chemicals used were of analytical grade. $0.5 \mathrm{M}$ zinc sulphamate, $0.5 \mathrm{M}$ nickel sulphamate, $50 \mathrm{~g} / \mathrm{L}$ boric acid, $60 \mathrm{~g} / \mathrm{L} \mathrm{NH}_{4} \mathrm{Cl}, 0.345 \mathrm{~g} / \mathrm{L} \beta$ - napthol, $0.9 \mathrm{~g} / \mathrm{L}$ sodium lauryl sulphate (SLS) were used for preparing the plating bath. The $\mathrm{pH}$ was maintained at $3-4$ and electrodeposition was carried out at $50{ }^{\circ} \mathrm{C}$, with stirring.

The cathodic current efficiency (CCE) was determined at the various different current densities studied. The electrodeposits were removed chemically by immersion in 1:1 $\mathrm{HNO}_{3}$ solution and the solution was analized for zinc and nickel by atomic absorption spectroscopy. The amount of nickel in the deposit was calculated from the difference in the mass of the deposit and that of the zinc determined.

The current efficiency is given by

$$
\% \text { current efficiency }=\frac{M x 100}{e_{\text {alloy }} Q}
$$

where $\mathrm{M}$ is the mass of the alloy deposit, $\mathrm{Q}$ is the quantity of electricity passed and $\mathrm{e}_{\text {alloy }}$ is the electrochemical equivalent

$$
e_{\text {alloy }}=e_{N i} \cdot e_{Z n} /\left(e_{N i} \cdot f_{Z n}+e_{Z n} \cdot f_{N i}\right)
$$

where $e_{\mathrm{Ni}}$ and $\mathrm{e}_{\mathrm{Zn}}$ are the electrochemical equivalent of the constituent metals. The density of the alloy was calculated by taking into consideration the fraction of the constituent metal.

\section{Cyclic voltammetry}

An all - glass three electrodes cell assembly of $80 \mathrm{~mL}$ capacity was used. A glassy carbon electrode $\left(0.07 \mathrm{~cm}^{2}\right)$, a large platinum foil and a saturated calomel electrode were used as working, counter and reference electrodes, respectively. 
To minimize IR drop, a finely drawn Luggin capillary was used. The desired potentials were swept $(-1500 \mathrm{mV}$ to $500 \mathrm{mV})$ using a propriety system from the USA at $10-100 \mathrm{mV} / \mathrm{sec}$. Zinc sulphamate $(0.5 \mathrm{M})$, nickel sulphamate $(0.5 \mathrm{M})$, boric acid $(0.1 \mathrm{M})$ solutions were used. Triethanolamine (TEA) solutions $(0.5$ $\mathrm{mM}$ to $2.5 \mathrm{mM}$ ) were used.

\section{Surface morphology}

Leica make metallurgical microscope was used to get optical micrographs. Hitachi S 3000H Scanning Electron Microscope was employed to follow surface morphology.

\section{Surface structure}

$\mathrm{X}$-ray diffraction studies were made using JEOL diffractometer using $\mathrm{CuK}_{\alpha}$ radiation $(0.1542 \mathrm{nM})$.

\section{Results}

\section{Current efficiency of alloy deposition}

Electrodeposition of zinc-nickel was carried out from the sulphamate bath, at various current densities ranging from 0.5 to $2.0 \mathrm{~A} \mathrm{dm}^{-2}$ for durations of 30 minutes each.

Table 1 presents the variation of cathode current efficiencies (CCE) with cathodic current densities. At all cathode current densities, the CCE of the alloy deposition was more than $70 \%$, the CCE of zinc deposition was greater than that of $\mathrm{Ni}$ deposition. The current efficiency increased to a maximum of $99 \%$ at the current density of $1.5 \mathrm{~A} \mathrm{dm}^{-2}$ and thereafter decreased due to hydrogen evolution. Hydrogen evolution was favoured on the alloy surface at higher current densities.

Table 1. Variation of cathodic current efficiencies (\%) with current densities.

\begin{tabular}{|c|c|c|}
\hline \multirow{2}{*}{$\begin{array}{c}\text { Current density } \\
\mathrm{A} / \mathrm{dm}^{2}\end{array}$} & \multicolumn{2}{|c|}{ CCE (\%) } \\
\cline { 2 - 3 } 0.5 & Without TEA in solution & With TEA in solution \\
\hline 0.8 & 70 & 70 \\
\hline 1.0 & 76 & 77 \\
\hline 1.2 & 85 & 86 \\
\hline 1.5 & 90 & 92 \\
\hline 1.8 & 99 & 99 \\
\hline 2.0 & 95 & 95 \\
\hline
\end{tabular}

Visual observation made on the electrodeposits revealed that in absence of TEA, uniform dark grey colour was seen at the corners. In presence of TEA and with increase in concentration of TEA, uniform, smooth, slate grey deposit was obtained (Table 2). 
When viewed using scanning electron microscope, the electrodeposits obtained in the absence of TEA exhibited crystallites with an average size of $12-16 \mu \mathrm{m}$ (Fig. 1a). Introduction of $0.25 \mathrm{mM}$ TEA to the plating solution made the surface of the deposit to exhibit smaller crystals of $10 \mu \mathrm{m}$ size covering the surface (Fig. 1b). XRD diffraction patterns obtained on the electrodeposits in the absence and presence of TEA are given in Fig. $2 \mathrm{a}$ and $2 \mathrm{~b}$. In the absence of TEA, $\mathrm{ZnCl}_{2} \cdot 2 \mathrm{NH}_{4} \mathrm{Cl}$ and $\delta \mathrm{Ni}_{3} \mathrm{Zn}_{22}$ phases were seen. In the presence of TEA additional $\mathrm{Zn}(\mathrm{OH})_{2}$ and $\gamma \mathrm{Ni}_{3} \mathrm{Zn}_{22}$ phases were observed (Table 3 ).

Table 2. Effect of TEA concentration on the nature of the alloy deposit.

\begin{tabular}{|c|l|l|}
\hline \multirow{2}{*}{$\begin{array}{c}\text { TEA } \\
(\mathrm{mL} / \mathrm{L})\end{array}$} & \multicolumn{2}{|c|}{ Nature of the deposit } \\
\cline { 2 - 3 } & Without $\mathrm{NH}_{4} \mathrm{Cl}$ in solution & With $60 \mathrm{~g} \mathrm{~L}^{-1} \mathrm{NH}_{4} \mathrm{Cl}$ in solution \\
\hline 0 & dark grey at the corners & uniform smooth grey \\
\hline 0.5 & uniform light grey & uniform light grey \\
\hline 1.0 & uniform smooth grey & smooth uniform grey \\
\hline 1.5 & semi bright, uniform & semi bright uniform \\
\hline 2.0 & light grey & light grey \\
\hline 2.5 & uniform smooth, slate grey & uniform, smooth, slate grey \\
\hline
\end{tabular}

Other conditions: $\beta$ - napthol $0.3 \mathrm{~g} \mathrm{~L}^{-1}$; sodium lauryl sulfate $0.9 \mathrm{~g} \mathrm{~L}^{-1}$; $\mathrm{pH} 3$ 4; temp. $328 \mathrm{~K}$; time 30 minutes; c.d.: $0.5 \mathrm{~A} \mathrm{dm}^{-2}$.

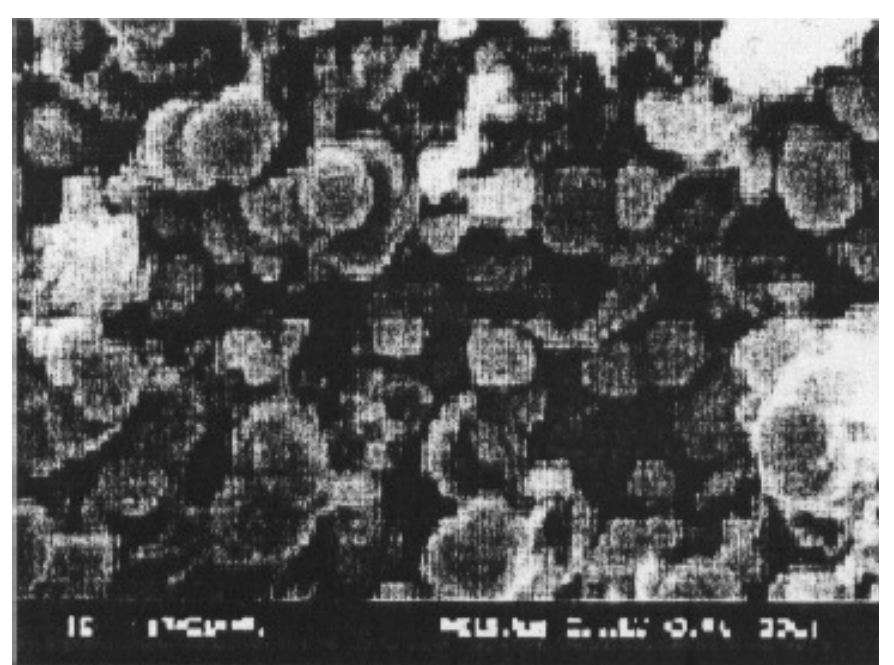

Figure 1a. SEM photograph of the deposit obtained from $\mathrm{Zn}-\mathrm{Ni}$ alloy plating bath without TEA addition. $\mathrm{T}=328 \mathrm{~K}$, c.d. $=0.5 \mathrm{~A} / \mathrm{dm}^{2}$, time $=30$ minutes. 


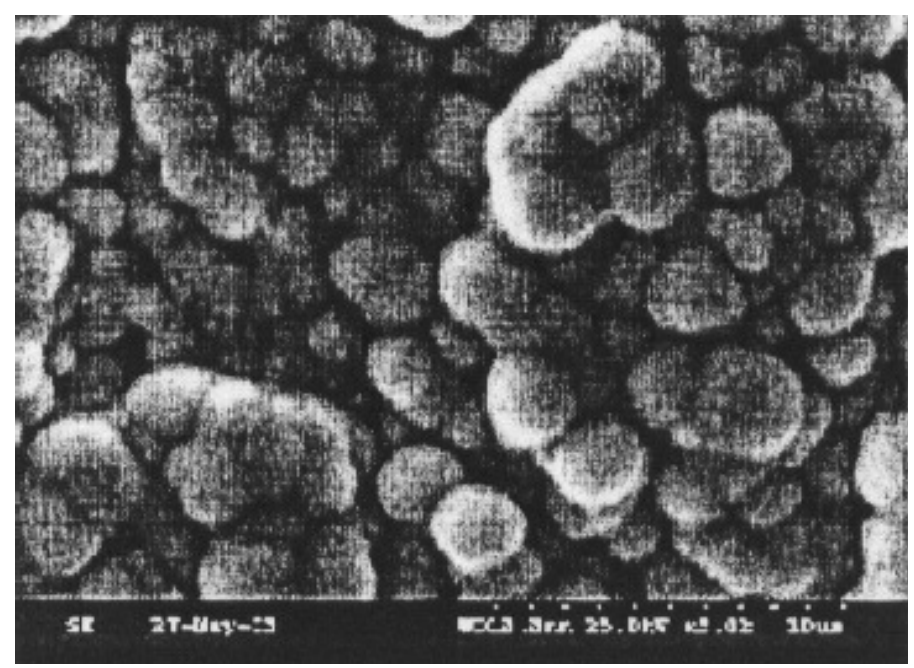

Figure 1b. SEM photograph of the deposit obtained in presence of $0.25 \mathrm{mM}$ TEA in the Zn-Ni alloy plating bath. $\mathrm{T}=328 \mathrm{~K}$, c.d. $=0.5 \mathrm{~A} / \mathrm{dm}^{2}$, time $=30$ minutes.

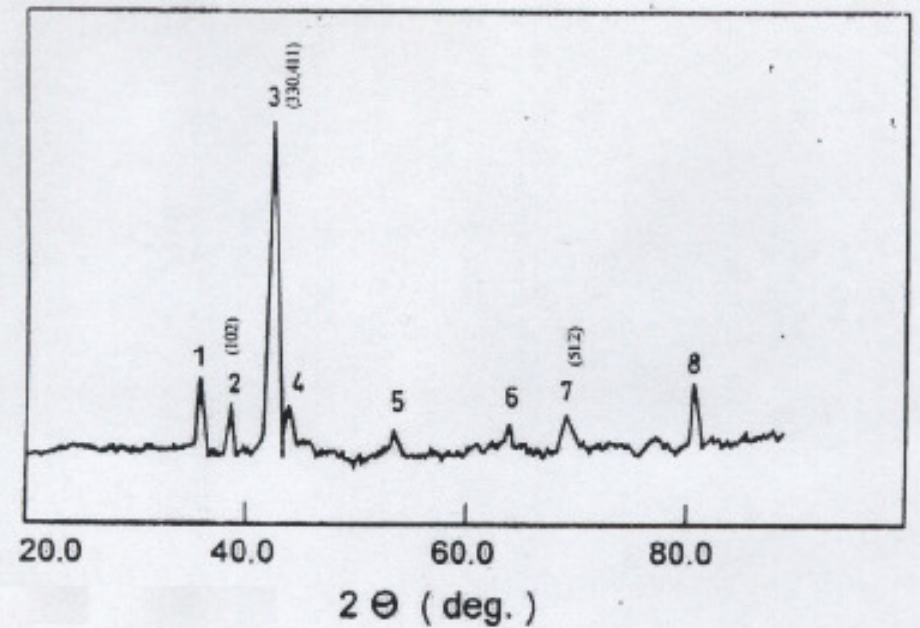

Figure 2a. XRD patterns of the electrodeposits obtained from $\mathrm{Zn}-\mathrm{Ni}$ alloy plating bath without TEA addition.

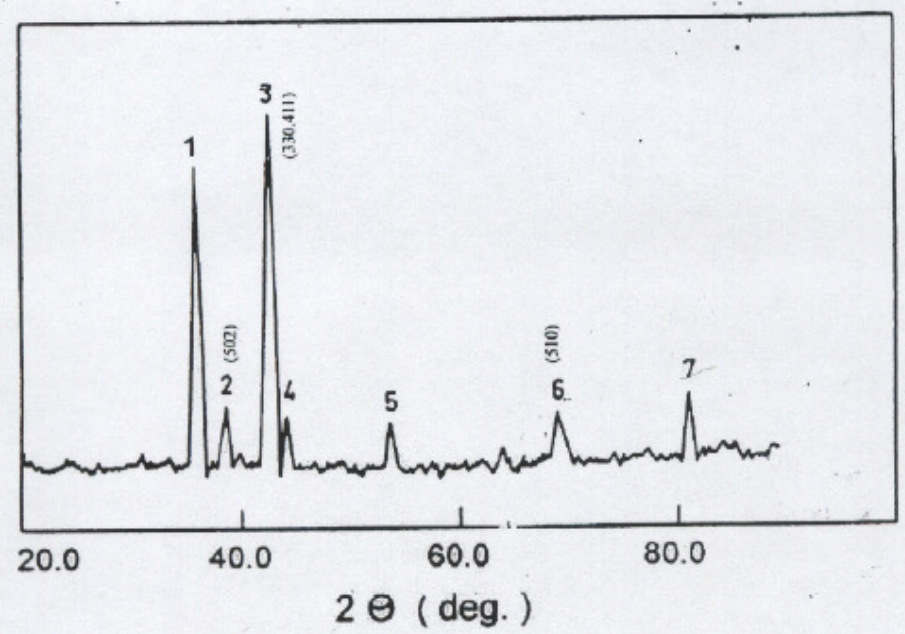

Figure 2b. XRD patterns of the electrodeposits obtained in presence of $0.25 \mathrm{mM}$ TEA in the $\mathrm{Zn}-\mathrm{Ni}$ alloy plating bath. 
Table 3. XRD analysis of $\mathrm{Zn}-\mathrm{Ni}$ alloy deposit obtained at $0.5 \mathrm{~A} / \mathrm{dm}^{2}$.

\begin{tabular}{|c|c|c|}
\hline Bath & Predominant phase & (hkl) \\
\hline + No TEA & $\begin{array}{l}\mathrm{\delta Ni}_{3} \mathrm{Zn}_{22} \\
\mathrm{ZnCl}_{2} .2 \mathrm{NH}_{4} \mathrm{Cl}\end{array}$ & $\begin{array}{l}(411)(330) \\
(102)\end{array}$ \\
\hline$+0.25 \mathrm{~mL} \mathrm{~L}^{-1} \mathrm{TEA}$ & $\begin{array}{l}\mathrm{\delta Ni}_{3} \mathrm{Zn}_{22} \\
\mathrm{ZnCl}_{2} .2 \mathrm{NH}_{4} \mathrm{Cl} \\
\mathrm{Zn}(\mathrm{OH})_{2} \\
\gamma \mathrm{Ni}_{3} \mathrm{Zn}_{22}\end{array}$ & $\begin{array}{l}(411)(330) \\
(102) \\
(512) \\
(554)\end{array}$ \\
\hline
\end{tabular}

Cyclic voltammograms obtained in $0.5 \mathrm{M}$ zinc sulphamate $+0.5 \mathrm{M}$ nickel sulphamate solutions without TEA are shown in Fig. 3. During forward scan three anodic peaks were seen at - $441 \mathrm{mV}$ (I), - $341 \mathrm{mV}$ (II) and at - $264 \mathrm{mV}$ (III). The reverse scan exhibited no peak. Introduction of $0.5 \mathrm{mM}$ TEA, did not alter the shape of the voltammogram. The three anodic peak current decreased (Table 4). Further increase of concentration of TEA caused the disappearances of second and third anodic peaks. The hydrogen evolution reaction was studied in absence and presence of TEA. Fig. 4 presents the linear sweep voltammogram for the hydrogen evolution reaction. At all cathodic potentials the hydrogen evolution currents decreased in the presence of TEA.

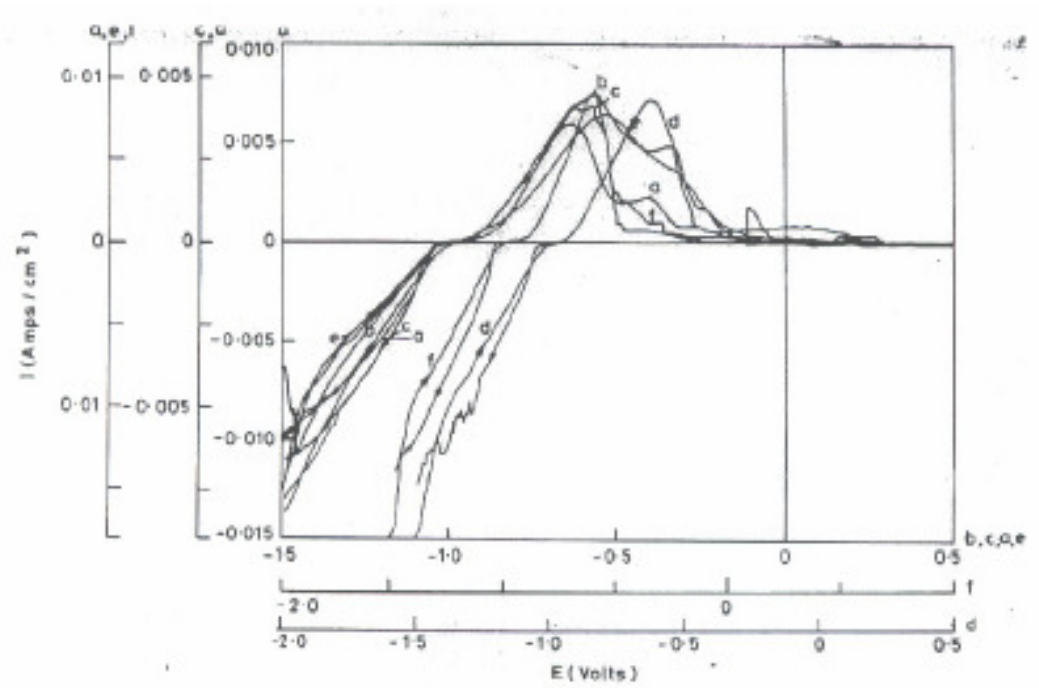

Figure 3. Cyclic voltammograms obtained in $0.5 \mathrm{M}$ zinc sulphamate $+0.5 \mathrm{M}$ nickel sulphamate $+0.1 \mathrm{M}$ boric acid - effect of TEA concentration: a) no TEA, b) $0.5 \mathrm{mM}$, c) $1.0 \mathrm{mM}$, d) $1.5 \mathrm{mM}$, e) $2.0 \mathrm{mM}$, and f) $2.5 \mathrm{mM}$. 
Table 4. Parameters derived from the cyclic voltammograms for the dissolution of zinc. Effect of TEA concentration $-25 \mathrm{mV} / \mathrm{sec}$.

\begin{tabular}{|c|c|c|c|c|c|c|c|}
\hline \multirow{2}{*}{$\begin{array}{c}\text { Conc. of } \\
\text { TEA }\end{array}$} & \multicolumn{3}{|c|}{ First anodic peak } & \multicolumn{2}{c|}{ Second anodic peak } & \multicolumn{2}{c|}{ Third anodic peak } \\
\cline { 2 - 8 } & Potential & Current & $\begin{array}{c}\text { Peak interse- } \\
\text { ction potential }\end{array}$ & Potential & Current & Potential & Current \\
$(\mathrm{mM})$ & $\begin{array}{c}\text { (mV vs. } \\
\text { SCE) }\end{array}$ & $(\mathrm{mA})$ & $(\mathrm{mV}$ vs. SCE) & $\begin{array}{c}(\mathrm{mV} \text { vs. } \\
\text { SCE) }\end{array}$ & $(\mathrm{mA})$ & $\begin{array}{c}(\mathrm{mV} \text { vs. } \\
\text { SCE) }\end{array}$ & $(\mathrm{mA})$ \\
\hline & & & & & & & \\
0 & -441 & 11.0 & -841 & -341 & 4.00 & -264 & 2.0 \\
0.5 & -558 & 9.0 & -852 & -295 & 3.73 & -240 & 1.58 \\
1.0 & -583 & 7.4 & -852 & - & - & - & - \\
1.5 & -590 & 6.8 & -862 & - & - & - & - \\
2.0 & -600 & 5.5 & -866 & - & - & - & - \\
2.5 & -617 & 4.0 & -889 & - & - & - & - \\
\hline
\end{tabular}

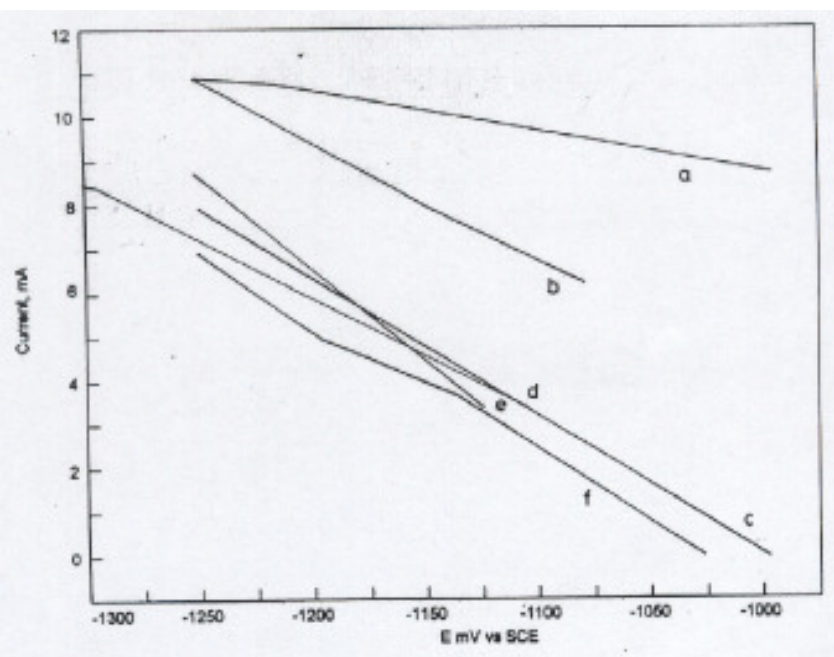

Figure 4. Linear sweep voltammograms for the hydrogen evolution reaction. a) No TEA, b) $0.5 \mathrm{mM}$, c) $1.0 \mathrm{mM}$, d) $1.5 \mathrm{mM}$, e) $2.0 \mathrm{mM}$, and f) $2.5 \mathrm{mM}$.

\section{Discussions}

The codeposition of iron group metals with zinc or with each other exhibits anomalous behaviour with respect to the relationship with the alloy composition. The retardation of the more noble metal by zinc was suggested as early as 1963 [4]. The deposition of the more noble metal was suppressed by the preferential deposition of hydroxides of less noble metal but not of the metal [5].

In the present study the appearance of $\mathrm{Zn}(\mathrm{OH})_{2}$ revealed that the deposition of nickel was suppressed. The deposition of nickel was found to be hindered by the underpotentially deposited zinc rather than by $\mathrm{Zn}(\mathrm{OH})_{2}$ when TEA was not present in the bath. The underpotential deposition of zinc was considered to inhibit either the formation of nickel clusters by deposition on the substrate or the growth of clusters by interacting with growing nickel. The interaction enhanced 
the polarization of nickel at constant current density resulting in anomalous codeposition. Studies on zinc-nickel alloy deposition from alkaline bath [6] revealed that the nickel content in the deposition layer was suppressed at high current density and that the nickel content in the alloy was not affected by the presence of TEA in the alkaline bath.

Organic compounds are added to the plating baths to increase polarization even at low current densities [7]. They improve the quality of the deposits in terms of adherence, size and grain homogenization [8]. Aldehydes and thiourea additions to zinc plating baths hindered zinc deposition $[9,10]$. Peptone additions increased the current efficiencies of tin and tin-zinc alloy deposition [11]. Triethanolamine and furfuraldehyde additions to the zinc plating baths hindered zinc deposition [12]. TEA in acidic $\mathrm{pH}$ complexed with zinc and underwent successive electronation [13].

In the present study, the hydroxyl ions formed during deposition reacted with zinc ions to form $\mathrm{Zn}(\mathrm{OH})_{2}$ which in turn got converted to $\mathrm{ZnCl}_{2} \cdot 2 \mathrm{NH}_{4} \mathrm{Cl}$. In the cyclic voltammograms the appearance of three anodic peaks suggests that the dissolution of zinc takes place at various energy sites or from different intermediate phases formed during dissolution. The first anodic peak potential being more active with TEA concentration in solution suggests that:

a) TEA hinders the dissolution by shifting the peak away from its reversible potential by adsorption on the surface;

b) the dissolution of zinc takes place as soluble zinc TEA complex due to the excess addition of TEA in the solution.

The number of peaks and peak currents depends on the amount of zinc deposited as various phases. The reversible potential of zinc / zinc sulphamate complex in solution is given by

$$
\mathrm{E}_{\mathrm{r}}^{\mathrm{Zn}}=\mathrm{E}_{\mathrm{r}, 0}^{\mathrm{Zn}}+2.303 \mathrm{RT} / 2 \mathrm{~F} \log \left[\mathrm{a}_{\text {zinc complex }}\right]
$$

where $\mathrm{a}_{\text {zinc complex }}$ is the activity of zinc sulphamate complex; $\mathrm{E}_{\mathrm{r}, 0}{ }^{\mathrm{Zn}}$ is the standard potential of zinc / zinc sulphamate complex.

The extrapolation of the linear segment of the rising portion of the anodic peak to zero current gives the reversible potential of the zinc / zinc sulphamate complex reaction. The first anodic peak intersection potential becoming active suggests that TEA hindered zinc deposition. Increase in the concentration of TEA decreased the first anodic peak current. If the decrease is due to the adsorption of TEA molecule on the electrode surface, then $\theta$, the surface coverage $=$

$$
\stackrel{1}{\mathrm{i}, \mathrm{a}}_{\mathrm{i}_{\mathrm{p}, \mathrm{a}}}-\mathrm{i}_{\mathrm{p}, \mathrm{a}}
$$

where $i_{p, a \_}$and $i_{p, a}$ are the first anodic peak current in presence and absence of TEA.

TEA hindered the hydrogen evolution by adsorption on the electrode surface by obeying Henry's isotherm. 


\section{Conclusions}

In the presence of triethanolamine in the zinc-nickel sulphamate bath the current efficiency of alloy deposition increased to a maximum of $99 \%$ at the current density of $1.5 \mathrm{~A} . \mathrm{dm}^{-2}$ and thereafter decreased. TEA adsorbed on the electrode surface obeying Henry's isotherm. On mild steel surfaces, uniform smooth slate grey deposit with smaller crystallites was produced, in presence of TEA in solution, and the electrodeposits exhibited additional $\mathrm{Zn}(\mathrm{OH})_{2}$ and $\gamma-\mathrm{Ni}_{3} \mathrm{Zn}_{22}$ phases. Hydrogen evolution was suppressed by TEA and thereby current efficiency is increased for alloy deposition.

\section{References}

1. N.R. Short, A. Abibsi and J.K. Dennis, Trans. Inst. Met. Finish 67 (1989) 73.

2. N. Zaki, Met. Finish June 1989, 57.

3. D.E. Hall, Plating Surf. Finish Nov 1983, 59.

4. A. Brenner, "Electrodeposition of Alloys - Principles and Practice" (Academic Press), N.Y., 1983.

5. H. Dahms and J. Croll, J. Electrochem. Soc. 112 (1965) 77.

6. Hwa Young Lee and Sung Gyu Kim, Surface and Coatings Technology 135 (2000) 69.

7. A. Aragon, M.G.F. Figuerroa and E. Gana, J. Appl. Electrochem. 22 (1992) 558.

8. V. Ravindran and V.S. Muralidharan, Bull. Electrochem. 16 (2000) 60.

9. S. Shabana Begum, C. Sivakumar, S.M. Mayanna and V.S. Muralidharan, Portugaliae Electrochimica Acta 18 (2000) 89.

10. S. Shabana Begum, V.S. Muralidharan and S.M. Mayanna, Portugaliae Electrochimica Acta 19 (2001) 121.

11. V.S. Vasantha, M. Pushpavanam, P. Kamaraj and V.S. Muralidharan, Trans. Inst. Met. Fin. (U K) 74 (1996) 28.

12. A.J. Rathinam, G.N.K. Ramesh Bapu and V.S. Muralidharan, Trans. SAEST 37 (2002) 149.

13. C. Sivakumar, V.S. Muralidharan, S. Shabana Begum and S.M. Mayanna, Indian J. Chem. Tech. 7 (2000) 202. 